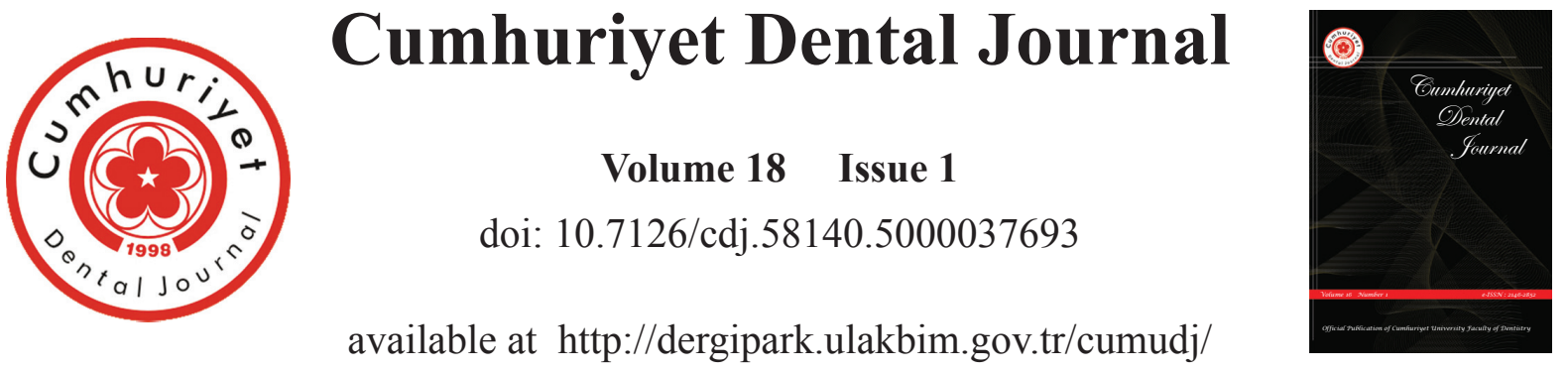

RESEARCH ARTICLE

\title{
Numerical analysis of the effect of implant geometry to stress distributions of the three different commercial dental implant system
}

Tolga Topkaya, MSc $c^{a}$, Murat Yavuz Solmaz, MSc, $P h D^{b}$, Serkan Dündar, DDS, $P h D^{c}$, Abubekir Eltas, DDS, $P h D^{d}$

${ }^{a}$ Department of Mechanical Engineering, Faculty of Engineering, Batman University, Batman, Turkey

${ }^{b}$ Department of Mechanical Engineering, Faculty of Engineering, Firat University, Elaziğ, Turkey

'Department of Periodontics, Faculty of Dentistry, Firat University, Elazığ, Turkey

${ }^{d}$ Department of Periodontics, Faculty of Dentistry, İnonu University, Malatya, Turkey

\section{A R T I C L E I N F O}

Article history:

Received 25 June 2014

Accepted 19 October 2014

\section{Keywords:}

Finite element analysis,

Dental implant design,

Stress distribution

\begin{abstract}
A B S T R A C T
Objectives: The success of dental implants is related to the quality, quantity of local bones, implant design and surgical technique. Implant diameter and length are accepted as key factors. Present work focuses to investigate the effect of titanium implant geometry to stress distributions in implant system.

Materials and Methods: For this purpose three different implant models which are currently being used in clinical cases constructed by using ANSYS Workbench 12.1. The stress distributions on components of implant system under static loadings were analyzed for all models.

Results: The maximum stress values that occurred in all components happen in the case of loading in which the Nucleoss T-4 (Nucleoss, Turkiye) implant is used, but the occurred lowest stress values happen in the case of Fr loading in which Nobel Active (Nobel Biocare, Zurich, Switzerland) implant is used. In all models, the maximum tensions have occurred in the neck region of the implants.

Conclusions: The crestal bone loss in the neck region of the implants reduced the long-term survival rate of implants. The length and the size of the implant are the two important factors in the stress distribution.
\end{abstract}

\section{INTRODUCTION}

Since the osseointegration of Brenemark ${ }^{1}$ was defined as the directly structural and functional connection, without having a fibrous tissue between the living bone tissue and implant surface under loading in1960s, the dental implant-supported prosthesis have been scientifically accepted and have

\footnotetext{
Correspondence to: Dr.Serkan Dundar, Frrat University, Faculty of Dentistry, Department of Periodontics, 23119, Elazıg, Campus, Turkey. E-mail:dtserkandundar@gmail.com, sdundar@firat.edu.tr

Note: A part of the information presented in this study was reported (oral presentation) at the $11^{\text {th }}$ International Symposium, Computer Methods in Biomechanics and Biomedical Engineering April 3-7, 2013, Salt Lake City, Utah, USA
} 
been a commen treatment choice in the case reconstructing of partial or total tooth loss. ${ }^{2}$

While the basic reason of early term loss of implant in endosseous dental implantation is the infection of periimplant tissues, the basic reason of implant-loss after the loading and osseointegration is the loss of bone which occurs on the implant neck region. The occurance of loss of periimplant bone after loading derives from the excessive stress that comes along the long axis of implant and/or having a wrong direction. The type of stress, the features of materials of which the implants and prosthesis are made, the implant geometry and it's surface structure, the quality and the quantity of bones around implant, the structure between bone and implant are the factors that determine the stress which affect the bones around implants. $^{3}$

Numerous implant concepts and implant types which have different shapes, dimensions, materials and different surface features have been presented to be use. ${ }^{3-7}$ Determining the reasons of the loss of implants, the analysis of the mechanic relations between bone and implant are important for planning of an effective, useful and dependable implant system., ${ }^{4,5}$ FEM (Finite Element Method) has taken part in literature as being a useful method to determine the tensions that occur on bone-implant intersurface during mechanic loading. With the help of FEM analysis, it has s suggested that the highest stress rate in endosseous dental implantation occurs in the occlusal part of cortical bone around implant. ${ }^{4}$ Many researchers have done lots of studies to increase the contact area on between the bone and implant intersurface and to lessen the crestal bone loss by diminishing the stress which affects the cortical alveolar bone. ${ }^{4,6,7,20,21}$ The studies which aim to increase the connection fields on the bone and implant intersurface concentrate on the size of implants, the implant geometry and/or the length of the implants. This study focuses to investigate the effect of titanium implant geometry to stress distributions in implant system.

\section{MATERIALS \& METHODS}

In this study, the implant and mandible, of which solid models were formed by using Solidworks Programme, were transferred to ANYSY Workbench Programme and finite element analysis were realized. The mandible has been modeled in Solidworks Programme with the help of computed tomography images. Figure 1 shows, the images obtained from computed tomography datums, Figure 2 shows, the three-dimensional model of the mandible.

In implant applications, the three implants used clinically have been modeled with the help of manufacturer data. The used implant models have been given in Figure 3. Nucleoss T4 (Nucleoss, Izmir, Turkiye), Nobel Replace (Nobel Biocare, Zurich, Switzerland) and Nobel Active (Nobel Biocare, Zurich, Switzerland) dental implants has been choosen owing to being a few of the types of commercial implants frequently used in the clinics of our country. While the Nobel Replace (Nobel Biocare, Zurich, Switzerland) is a tissue level implant; Nucleoss T4 (Nucleoss, Izmir, Turkiye) and Nobel Active (Nobel Biocare, Zurich, Switzerland) are bone level implants. All three implants have grooves in the neck of them. The apical is right angled in all three implants. While Nobel Replace (Nobel Biocare, Zurich, Switzerland) and the Nobel Active (Nobel Biocare, Zurich, Switzerland) implants have v-shaped grooves, Nucleoss T4 (Nucleoss, Izmir, Turkiye) implant has double hellical groove. Nucleoss T4 (Nucleoss, Izmir, Turkiye) implant is smaller than Nobel Replace (Nobel Biocare, Zurich, Switzerland) and Nobel Active (Nobel Biocare, Zurich, Switzerland) implants in diameter and length. 


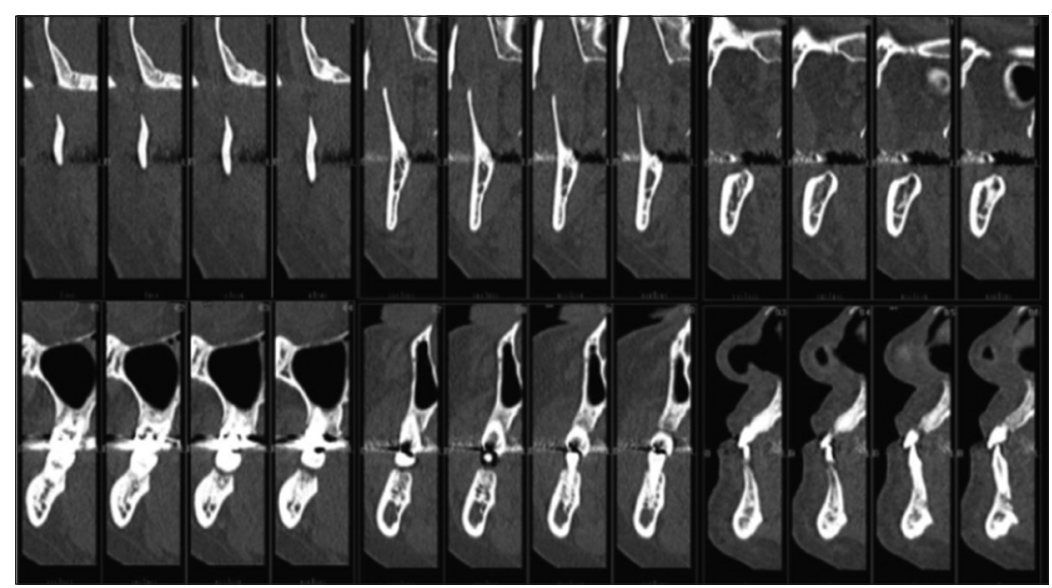

Figure 1. Computed tomography images

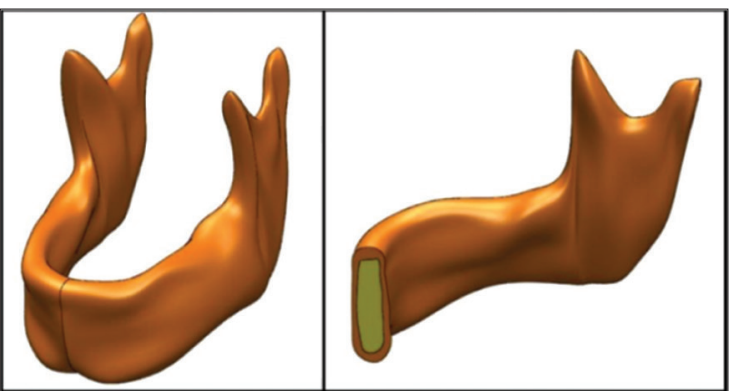

Figure 2. The three-dimensional model of the mandible

The constructed mandible models were divided into finite elements and boundry conditions and they were applied by using the mounting of porselein prosthesis, implant models, abutment, metal support and adhesive layer. In the Table 1 , the mechanic features of the used materials have been given.

Dental implants are exposed to different loads. Three different loads were applied to models in order to examine the effect of different loads to tension distributions. In Figure 4, the application of the load to models has been given. In the figure, $\theta$ shows the angle degree of the load, F shows the amount of the load. If the applied loads are vertical, $\mathrm{F}_{1}$ is $100 \mathrm{~N}^{4}$, if $\mathrm{F}$ at an agle of 15 degrees with the vertical axis, F $11100 \mathrm{~N}^{6}$, if $\mathrm{F}$ at an angle of 30 degrees with the vertical axis, F111 150 N. ${ }^{8}$

\section{RESULTS}

When the result of the work were examined, the maximum stress values were obtained in Nucleoss T-4 (Nucleoss, Izmir, Turkiye) for all components the lowest stress values were obtained in Nobel Active (Nobel Biocare, Zurich, Switzerland).

In Figure 5, abutment and screws which are the primary elements that exposed to stress are shown. When we look the figure, we see. Additionally, in the model in which only Nucleoss T-4(Nucleoss, Izmir, Turkiye) implant is used, it has been seen that the stress occuring in abutment during F11 and F11 loading is higher than the stress value occuring in implant. Within 3 different kinds of implant, the stress distributions of F111 during the loading in which value of maximum stress occurs has been given in Figure 6.

When we examine the stress distributions, we notice that the stresses concentrate on the neck region of the implant and the maximum stress values occur on the neck region of the implant in all three implants.

\section{DISCUSSION}

FEM is a numerical method that is used to analyze the stress and deformations occuring in the structure of a geometrical 
Table 1. The mechanical features of the used materials have been given.

\begin{tabular}{|c|c|c|c|c|}
\hline & $\begin{array}{c}\text { Young Module } \\
\text { (GPa) }\end{array}$ & Poisson Ratio & Yield Strength (Mpa) & Tensile Strength (MPa) \\
\hline Ti6Al4V & 114 & 0,34 & 360 & 930 \\
\hline Adhesive Layer & $s$ & 0,35 & - & 161 \\
\hline Porcelain & 96 & 0,25 & - & 400 \\
\hline Trubecular Bone & 0,49 & 0,3 & - & 23 \\
\hline Cortical Bone & 14,7 & 0,3 & . & 88 \\
\hline
\end{tabular}

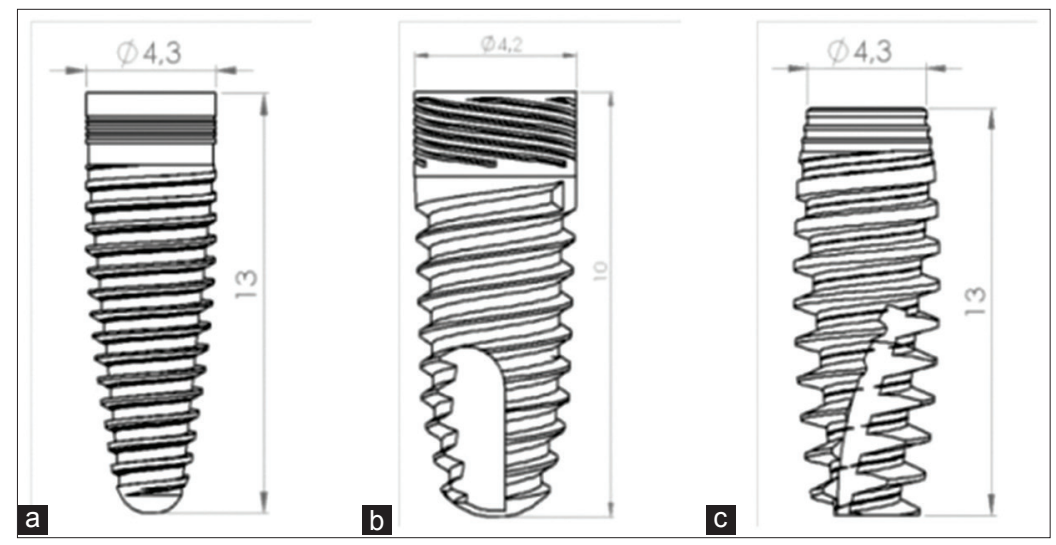

Figure 3. The implant models used in this study: a- Nobel Replace (Nobel Biocare, Zurich, Switzerland). b- Nucleoss T-4 (Nucleoss,Izmir,Turkiye), c- Nobel Active (Nobel Biocare, Zurich, Switzerland).

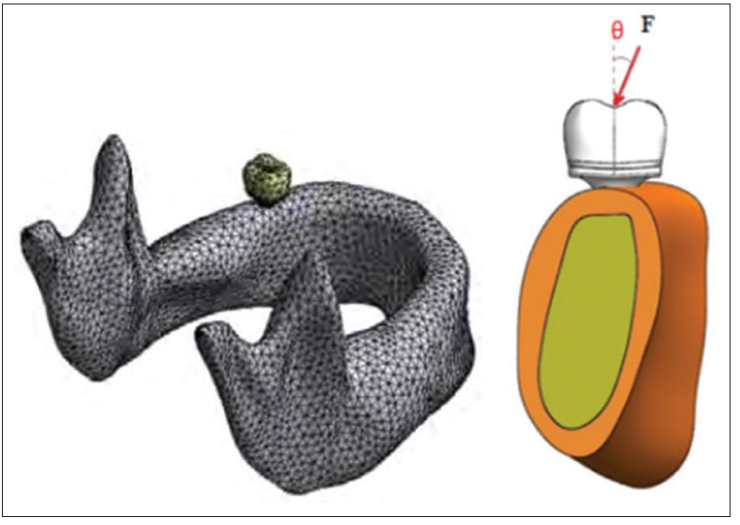

Figure 4. The application of the load to models

model. FEM has taken part in implant tecnology as not only being a method used in root-form implants and for the evalution and analysis of forces that affect bone/implant interface but also being a method used in the evalution of various clinic and protetic choices., ${ }^{3,4,6-8}$ This method aims to solve complex problems with mathematical methods by dividing them into simple and small structures related with each other. ${ }^{3}$

In this study, three different commercial osseintegrated implants were examined with FEM. All the studied implants on the same model have been planted on the mandible first molar region. Until now in most studies, the changes occurred in implant and surrounding bone have been examined by looking the stress values of Von Misses. ${ }^{9,10}$ So, we approved to examine Von Misses stress values based on these studies.

The reason why biomechanical behaviours obtained from this study are 


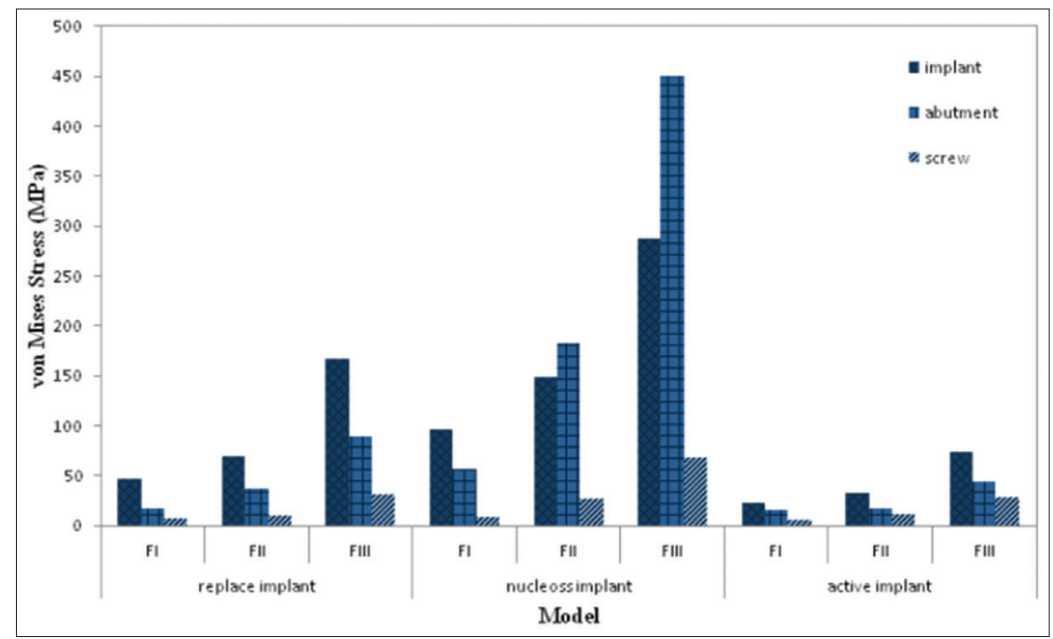

Figure 5. The maximum stress values occuring in implant, abutment and screws

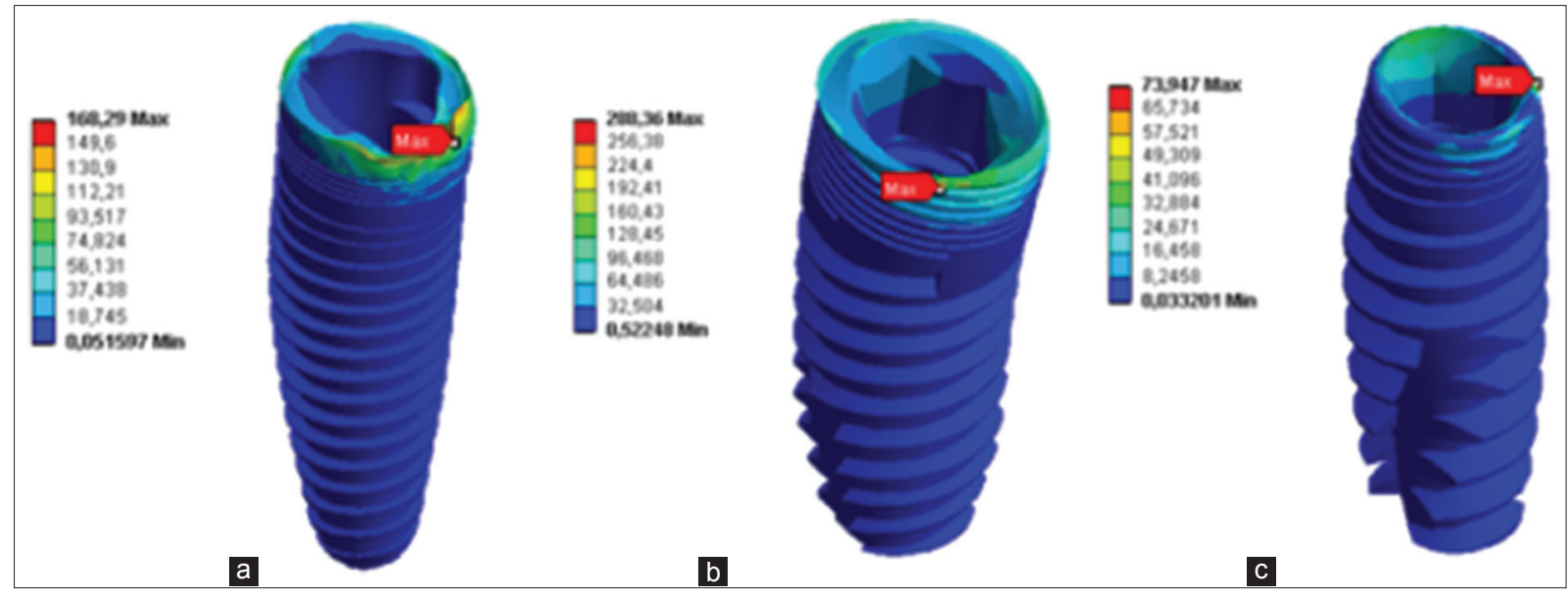

Figure 6. The stress distributions occuring in implants (a-Nobel Replace (Nobel Biocare, Zurich, Switzerland), b-Nucleoss T-4(Nucleoss,Izmir,Turkiye), c- Nobel Active (Nobel Biocare, Zurich, Switzerland)).

different is that because implant systems have different parameter shapes. The reason why the obtained results are different for all is that, in accordance with the other studies, the transmission of stress between bone and implant is thougt to be basically affected by the shape and size of implant. ${ }^{11,12}$

According to former studies done, the length and diameter of the implant are emphasized to be the two important parameters on the stress distribution to bone around implant. ${ }^{13}$ In accordance with this, the basic reason of the stresses occurred in in Nucleoss T-4 (Nucleoss, Izmir,
Turkiye) model to be higher than the other models is that their length and diameter values are smaller than the other models.

The amount and distributions of the stresses coming to bone/implant interface are affected by the length of the implant. ${ }^{14}$ In FEM analysis done in former studies, it was put forward that an increase in implant length causes a decrease in crestal bone stress values. ${ }^{6}$ In accordance with this results, the clinic studies state that, contrary to short implants, the long ones can be kept in the mouth for a longer time. ${ }^{15,} 16$ At the same time, there are studies which point that the diameter of 
implant is more important than the length of the implant, too. ${ }^{8,13,17}$ According to FEM studies, the possible reason of this result is that because the stress distribution in bone socket is uneven and the bone on implant neck exposed to maximum stress. ${ }^{17}$

In FEM studies on titanium implants, it is informed that stress intensity occurs in implant neck region. ${ }^{18}$ In this study, stresses coming out in implants concentrate on implant neck region and the maximum Von-Misses stress values emerge on these points too. The result obtained from clinic and histomorphometric studies is that bone loss occurred on implant neck region is an important parameter in implant loss during the period after loading. ${ }^{17-19}$ In Nucleoss T-4 (Nucleoss, Izmir, Turkiye) model which is smaller in diameter than the other implants, the stress of neck region is higher. The implants which have a larger neck region can resist more to masticatory forces, can be kept in mouth longer-terms and can cause less crestal bone loss. ${ }^{4,17}$

In literature, when three-dimensional finite element analysis on dental implants are examined, it is seen that the non-axial forces are more destructive than the axial forces, and non-axial forces couse more stress accumulation in periimplant bone than axial forces do. ${ }^{20,21}$ From this study, in all three implant types, it is clearly seen that a rise in loading force angle with vertical axis increases the stress distribution in implant system. These results are consistent with previous studies. In addidion to excessive stress in all forces in Nucleos T-4 (Nucleoss, Izmir, Turkiye) model, the reason of the stresses coming out in abutments in especially F11 and F111 forces is, as mentioned previously, Nucleos T-4 (Nucleoss, Izmir, Turkiye) implant are smaller in length and diameter than the others. ${ }^{12,13}$

In most single molar implant-supported prostheses, the bone loss occurred as a result of excessive oclusal loading have been stated to come ahead of implant structures. ${ }^{22}$ As the increased oclusal forces can couse implant losses by leading to crestal bone loss, it can also couse abutment and implant losses by leading to abutment screw loosening. ${ }^{23}$

In implant losses after loading, implant neck fractures should be taken in consideration. The writers have determined an implant fracture rate of $\% 14$ in a study on standard Nobel Biocare (Zurich, Switzerland) implant-supported single molars. ${ }^{22}$ This study has been done on mandible posterior region. When obtained results have been examined, maximum stress values occurred in all components have been determined to come out in Nucleoss T-4 (Nucleoss, Izmir, Turkiye) implant-used model in the case of Fill loading. The reoccurance of most stresses in abutment in both F11 and F111 forces that have angle with vertical axis, the increasing of stress distributions in direct proportion to the increase in the angle with vertical load are remarkable in terms of axial forces. Choosing largediameter and long implants by taking the length of bone and anatomic limitations into account because of excessive forces occuring during the selection of implant on mandible posterior region can increase the survival rate of the implant in the mouth. Large-diameter and long implants used on mandible posterior region can perform better biomechanical properties with the increasing surface, increasing fracture resistance and increasing abutment stability. ${ }^{23}$

\section{CONCLUSION}

Based on the limited results of this study, we can say that implant geometry is an important parameter in the distribution of biomechanic forces on implant and periimplant tissues. High-emergence of stress distribution, in implants which are smaller in length and diameter put 
forward that length and diameter are the two important factors in the distribution of forces. In all models, maximum stresses occur on implant neck region. The crestal bone loss on implant neck region diminishes the survival rate of implants in the mouth in long terms. In the implants which are exposed to more masticatory force on lower jaw posterior regions, especially the use of large-diameter and long implants can be evaluated as parameters which increase the survival rate in the mouth. There is need of more laboratory and clinical studies in order to obtain appropriate shapegeometry that provide longer term clinical use of implants.

Disclosure: We have not a financial relationship with the organization that sponsored the research.

\section{REFERENCES}

1. Branemark PI, Adell R, Breine $U$, Hansson BO, Lindstrom J, Ohlsson A. Intra-osseous anchorage of dental prostheses. I. Experimental studies. Scand J Plast Reconstr Surg 1969;3:81-100.

2. Buser $D$, Mericske-Stern $R$, Bernard JP, Behneke A, Behneke N, Hirt $\mathrm{HP}$, et al. Long-term evaluation of non-submerged ITI implants. Part 1: 8-year life table analysis of a prospective multi-center study with 2359 implants. Clin Oral Implants Res 1997;8:161-172.

3. Bozkaya D, Muftu S, Muftu A. Evaluation of load transfer characteristics of five different implants in compact bone at different load levels by finite elements analysis. J Prosthet Dent 2004;92:523-530.

4. Petrie CS, Williams JL. Comparative evaluation of implant designs: influence of diameter, length, and taper on strains in the alveolar crest. A three-dimensional finite-element analysis. Clin Oral Implants Res 2005;16:486-494.

5. Acar A, İnan Ö. İmplant destekli protezlerde okluzyon. Cumhuriyet Üniversitesi Dişhekimliği Fakültesi Dergisi 2001;4,1:52-56.

6. Chun HJ, Cheong SY, Han JH, Heo SJ, Chung JP, Rhyu IC, et al. Evaluation of design parameters of osseointegrated dental implants using finite element analysis. J Oral Rehabil 2002;29:565-574.

7. Tada S, Stegaroiu R, Kitamura E, Miyakawa O, Kusakari H. Influence of implant design and bone quality on stress/strain distribution in bone around implants: a 3-dimensional finite element analysis. Int $\mathrm{J}$ Oral Maxillofac Implants 2003;18:357-368.

8. Anitua E, Tapia R, Luzuriaga F, Orive G. Influence of implant length, diameter, and geometry on stress distribution: a finite element analysis. Int J Periodontics Restorative Dent 2010;30:89-95.

9. Teixeira ER, Sato Y, Akagawa Y, Shindoi N. A comparative evaluation of mandibular finite element models with different lengths and elements for implant biomechanics. J Oral Rehabil 1998;25:299-303.

10. Geng JP, Ma QS, Xu W, Tan KB, Liu GR. Finite element analysis of four thread-form configurations in a stepped screw implant. J Oral Rehabil 2004;31:233-239.

11. Akpinar I, Demirel F, Parnas L, Sahin S. A comparison of stress and strain distribution characteristics of two different rigid implant designs for distal-extension fixed prostheses. Quintessence Int 1996;27:11-17.

12. Holmgren EP, Seckinger RJ, Kilgren LM, Mante F. Evaluating parameters of osseointegrated dental implants using finite element analysis-a two-dimensional comparative study examining the effects of 
implant diameter, implant shape, and load direction. J Oral Implantol 1998;24:80-88.

13. Van Staden RC, Guan H, Loo YC. Application of the finite element method in dental implant research. Comput Methods Biomech Biomed Engin 2006;9:257-270.

14. Baggi L, Cappelloni I, Di Girolamo M, Maceri F, Vairo G. The influence of implant diameter and length on stress distribution of osseointegrated implants related to crestal bone geometry: a three-dimensional finite element analysis. J Prosthet Dent 2008;100:422-431.

15. Winkler $S$, Morris HF, Ochi S. Implant survival to 36 months as related to length and diameter. Ann Periodontol 2000;5:22-31.

16. Ivanoff CJ, Grondahl K, Sennerby L, Bergstrom C, Lekholm U. Influence of variations in implant diameters: a 3- to 5-year retrospective clinical report. Int J Oral Maxillofac Implants 1999;14:173-180.

17. Himmlova L, Dostalova T, Kacovsky A, Konvickova S. Influence of implant length and diameter on stress distribution: a finite element analysis. J Prosthet Dent 2004;91:2025.
18. Geng JP, Tan KB, Liu GR. Application of finite element analysis in implant dentistry: a review of the literature. J Prosthet Dent 2001;85:585-598.

19. Wiskott HW, Belser UC. Lack of integration of smooth titanium surfaces: a working hypothesis based on strains generated in the surrounding bone. Clin Oral Implants Res 1999;10:429-444.

20. Papavasiliou G, Kamposiora P, Bayne SC, Felton DA. Three-dimensional finite element analysis of stressdistribution around single tooth implants as a function of bony support, prosthesis type, and loading during function. J Prosthet Dent 1996;76:633-640.

21. Kitamura E, Stegaroiu R, Nomura $S$, Miyakawa O. Influence of marginal bone resorption on stress around an implant-a three-dimensional finite element analysis. J Oral Rehabil 2005;32:279-286.

22. Rangert $B$, Krogh $P H$, Langer $B$, Van Roekel N. Bending overload and implant fracture: a retrospective clinical analysis. Int J Oral Maxillofac Implants 1995;10:326-334.

23. Misch CE. Contemporaray Implant Dentisrty. Mosby Elsevier 2008; Third edition:337

How to cite this article: Tolga Topkaya, Murat Yavuz Solmaz, Serkan Dündar, Abubekir Eltas. Numerical analysis of the effect of implant geometry to stress distributions of the three different commercial dental implant system. Cumhuriyet Dent J 2015;18(1):17-24. 